\title{
Retroperitoneal cellular schwannoma (CS): a potential pitfall of malignancy. Report of a case and review of the literature
}

\author{
Francesca Longo ${ }^{1}$, Giuseppe Musumeci ${ }^{2 *}$, Gerardo Ferrara ${ }^{3}$, Claudia Trombatore ${ }^{4}$ and Gaetano Magro ${ }^{1}$
}

*Correspondence: g.musumeci@unict.it

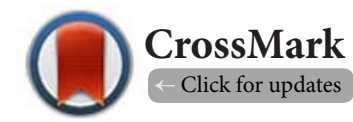

\begin{abstract}
'Department of Medical and Surgical Sciences and Advanced Technologies, G.F. Ingrassia, Azienda Ospedaliero-Universitaria “PoliclinicoVittorio Emanuele", Anatomic Pathology Section, University of Catania, Catania, Italy.

${ }^{2}$ Department of Biomedical and Biotechnological Sciences, Human Anatomy and Histology Section, School of Medicine, University of Catania, Catania, Italy.

"U.O.C. Anatomic Pathology, Azienda Ospedaliera "G. Rummo", Benevento, Italy.

${ }^{4}$ Radiodiagnostic and Radiotherapy Unit, University Hospital “Policlinico-Vittorio Emanuele”, University of Catania, Catania, Italy.
\end{abstract}

\begin{abstract}
Cellular Schwannoma (CS) is a well-recognized morphological variant of schwannoma, which has been reported in many usual and unusual sites. We herein report a rare case of a bulky, retroperitoneal cellular schwannoma showing challenging radiological and morphological features. Due to large size and ill-defined margins at CT examination a malignant soft tissue tumor (sarcoma) was suggested. At histological examination high cellularity and co-existence of several growth patterns, such as fascicular, storiform and herringbone patterns, contributed to make difficult its recognition as schwannoma. The present case emphasizes the possibility that retroperitoneal CS can represent a potential diagnostic pitfall of malignancy. Awareness of the possibility that this unusual variant of schwannoma may occur in the retroperitoneum is crucial to avoid potential confusion with malignant tumors, especially when evaluating small biopsies.
\end{abstract}

Keywords: Cellular schwannoma, retroperitoneum, imaging, sarcoma, immunohistochemistry

\section{Introduction}

Cellular schwannoma (CS) is a well-recognized variant of schwannoma which deviates from classic type schwannoma for the absence of the so-called "Verocay bodies", while it is exclusively or predominantly composed of "Antoni A" areas [1]. CS occurs in an age group similar to the classic schwannoma, with a peak incidence from the fourth to sixth decades of life $[1,2]$. There is only one case of CS reported during pregnancy [3]. Compared to the classic type, CS tends to develop more often in deep cavities, such as retroperitoneum [4-6], posterior mediastinum [7], and in paravertebral sites, with only rare cases reported in pleura [8], lung [9-11], pelvis $[\mathbf{1 0 , 1 2}]$ and gastrointestinal tract [13-15]. The cranial nerves may also be affected, especially the fifth [16] and the eighth [17-19]; less commonly, abducens nervus [20], hypoglossal nervus [21] and intercostal nerves [22] are involved. Only about one-fourth of all CS develops in the deep soft tissues of the extremities [23-25].
Rare cases of CS are described in pharynx [26,27], intrasellar region, parasellar region [28], cranial fossa [29,30], retrobulbar site [31], oral mucosa [32], paranasal sinuses [33], mandible $[34,35]$, and vagina [36]. Only one case of spinal epidural schwannoma in an infant has been reported [12]. Clinically CS may be asymptomatic and discovered occasionally by radiological images, or produce neurological symptoms. Like classic schwannoma, at gross examination, CS appears well circumscribed, encapsuled, and occasionally exhibiting a plexiform growth pattern. At cut section tumor has a homogeneous appearance and it is tan in color; sometimes hemorrhagic or degenerative cystic areas can be observed. At histological examination, CS is composed predominantly or exsclusively of "Antoni A" areas, while "Antoni B" areas, which frequently results in the formation of the "so-called" Verocay bodies, may be absent or focally detected in less than 10\% of the tumors. As CS is composed of closely packed spindle 
Longo et al. Journal of Histology \& Histopathology 2014,

http://www.hoajonline.com/journals/pdf/2055-091X-1-14.pdf

cells arranged in intersecting fascicles with several growth patterns, this tumor can represent a potential diagnostic pitfall, especially for pathologists who are unfamiliar with this entity. In this regard CS can be confused with other malignant soft tissue tumors, which partially share similar architectural patterns, including adult-type fibrosarcoma, leiomyosarcoma, monophasic synovial sarcoma, and malignant peripheral nerve sheath tumor. Mitotic activity can be detected but usually is low ( $<4$ mitoses/10HPF). Small foci of necrosis, identified in up to $10 \%$ of cases, are admitted and usually considered traumainduced [1]. Another characteristic morphological finding of CS is the presence of sub-capsular lymphoid aggregates. Bone erosion may be present [1]. Like classic schwannoma, CS displays diffuse and strong immunoreactivity for $\mathrm{S} 100$ protein. During infancy and childhood, CS, due to its high cellularity, herringbone-like pattern, mitotic activity and occasional bone erosion, often may be misdiagnosed as congenital hamartoma (fascicular schwannoma) or dramatically as plexiform malignant peripheral nerve sheath tumors $[2,15,37-42]$.

\section{Case presentation}

A 32 year-old woman presented a 4-month history of intermittent pelvic pain. Physical examination, laboratory tests and her past medical history were unremarkable. As an abdominal ultrasound revealed a retroperitoneal solid mass, the patient underwent abdomino-pelvic computed tomography (TC), which showed a bulky, solid mass, localized in the left lumbo-aortic region (Figure 1). The mass was attached to the aorta and iliac artery wall; the axial image showed a retroperitoneal mass localized anteriorly to the lumbar spine, extending to the left psoas compartment, where the tumor was undissociable from the medial profile of the ipsilateral psoas muscle, which is markedly splayed and dislocated on the left side of the abdomen. There were no signs of bone erosion. Left common iliac artery and vein, in close contact with the mass, were compressed and displaced to the right of the midline, in absence of encasement and infiltration (Figure 1). The mass showed a round hypodense central area and presented a moderate enhancement after e.v. administration of the contrast agent. Due to large size $(9 \mathrm{~cm})$, solid internal structure, ill-defined left margin, in correspondence of which the mass appeared to be not dissociable from the ipsilateral psoas muscle, the possibility of a malignant soft tissue tumor (sarcoma) was suggested. The patient, after having signed her informed consent, was submitted to surgical resection of the tumor mass. The patient is doing well and is without any recurrence 16 months after surgery.

\section{Materials and methods}

The surgical specimen was submitted for histological examination in neutral-buffered $10 \%$ formalin, dehydrated using standard techniques, embedded in paraffin, cut to $5 \mu \mathrm{m}$, and stained with hematoxylin and eosin. Immunohistochemical studies were performed with the labeled streptavidin-biotin

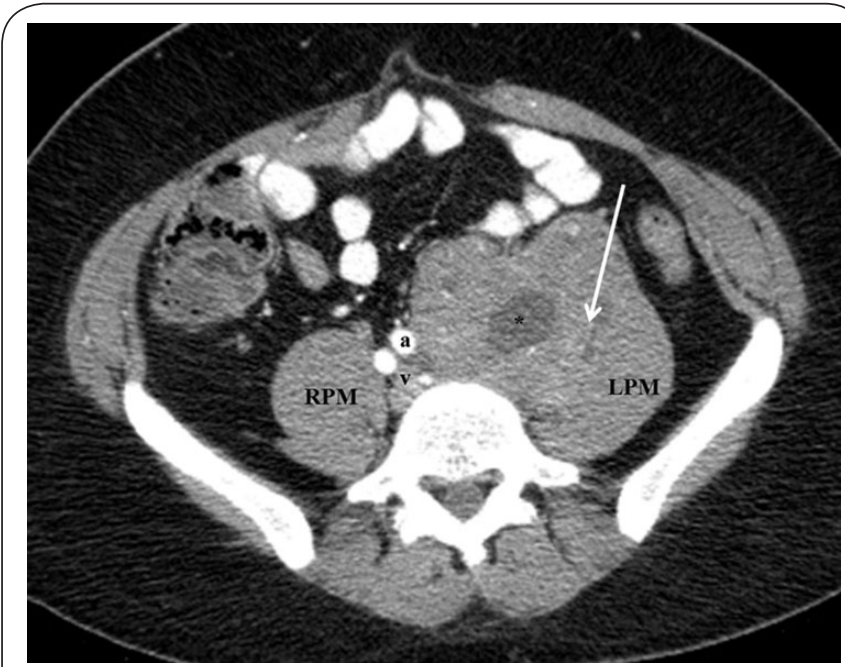

Figure 1. CT examination. The axial image shows a retroperitoneal mass (arrow) localized anteriorly to the lumbar spine and extending to the left psoas compartment where the tumor is not dissociable from the medial profile of the ipsilateral psoas muscle (LPM) which is markedly splayed and dislocated on the left side of the abdomen. There are no signs of bone erosion. Left common iliac artery (a) and vein (v), in close contact with the mass, are compressed and displaced to the right of the midline, in absence of encasement and infiltration. The mass shows a round hypodense central area $\left({ }^{*}\right)$ and presents a moderate enhancement after e.v. administration of the contrast agent.

RPM=right psoas muscle; LPM=left psoas muscle; $a=l e f t$ common iliac artery; $\mathrm{v}=\mathrm{left}$ common iliac vein

peroxidase detection system using the Ventana automated immunostainer (Ventana Medical Systems, Tucson, AZ). The following antibodies were tested: vimentin, S100 protein, CD31, a-smooth muscle actin, desmin, myogenin, CD34, CD99, CD117, pan-cytokeratins, EMA (epithelial membrane antigen), bcl2, ALK-protein (all from DakoCytomation, Glostrup, Denmark). Negative controls for the staining were slides stained with omission of the primary antibody.

\section{Pathological findings}

Gross examination revealed a tumor mass with well-defined margins, measuring $9 \mathrm{~cm}$ in its greatest diameter, and with a lobulated, smooth external surface. The cut section showed a solid lesion with homogeneous appearance, firm in consistency and whitish in color. Focally, hemorragic areas were seen. Histologically, a highly cellular tumor, completely circumscribed by a thick, fibrous capsule, was seen at low magnification (Figure 2). Tumor was composed of blandlooking spindle-shaped cells variably arranged in intersecting long or short fascicles (Figure 3). Focally, neoplastic cells exhibited a storiform or herringbone growth patterns. Neoplastic cells had relatively abundant pale to eosinophilic cytoplasm and oval nuclei with rare nucleoli. Mitotic activity was low ( $<1$ mitosis $\times 10 \mathrm{HPF})$. Small foci of necrosis were idien- 


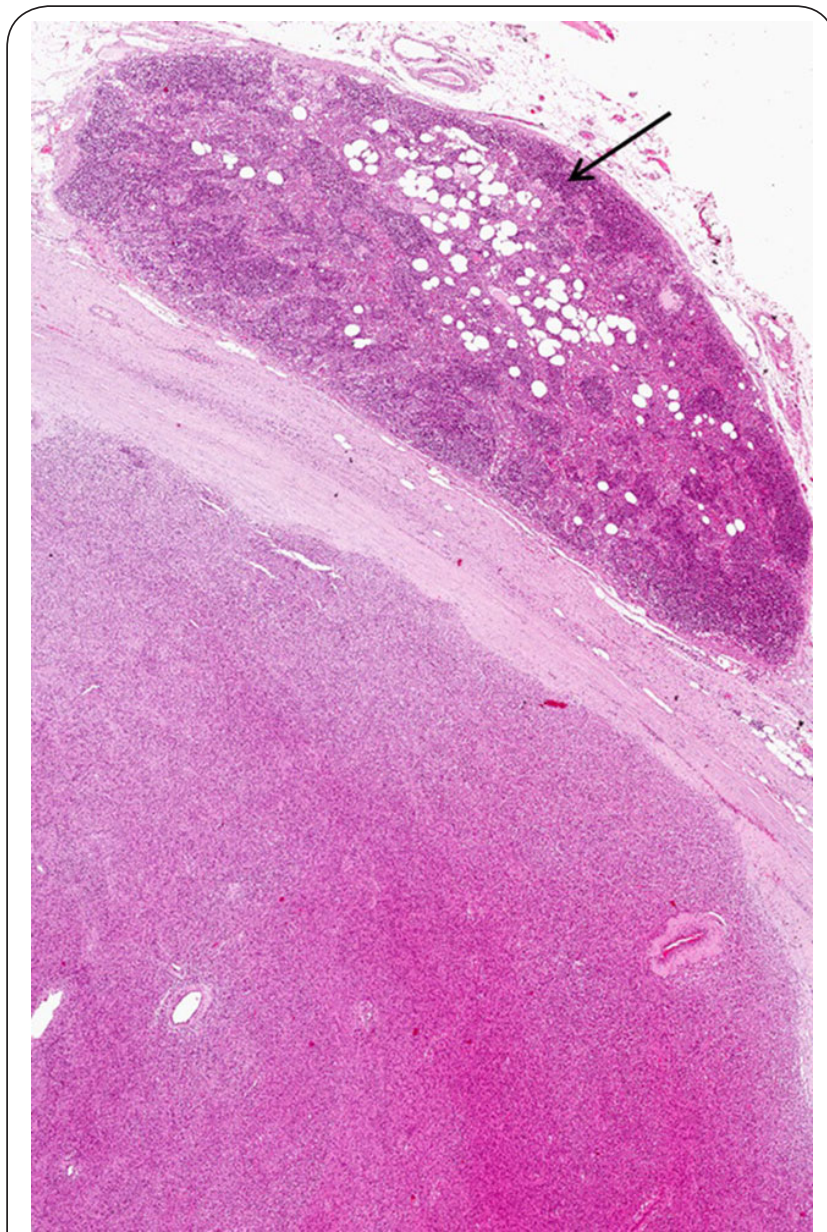

Figure 2. Low magnification showing an encapsulated, highly cellular tumor. A normal appearing lymph node (arrow) is seen to be attached to tumor capsule (haematoxylin and eosin staining; original magnification $\mathrm{x} 40$ ).

tified. Nuclear pleomorphism and atypical mitoses were not seen. Tumor contained numerous small-to mediumsized blood vessels with thick hyalinized walls (Figure 4). Interestingly, inflammatory cells, including lymphocytes, plasmacells, and foamy histocytes, were scattered troughout the tumor (Figure 5). Notably, a central tumor area showed degenerative changes characterized by extensive edema, focal necrosis, and chronic inflammation (mainly foamy histiocytes). A normal appearing lymph node was attached to tumor capsule. Immunohistochemically, neoplastic cells were diffusely and strongly stained with vimentin and S100 protein (Figure 6). No immunoreactivity was obtained with any of the other antibodies tested. Based on both morphological and immunohistochemical features the diagnosis of "cellular schwannoma" was rendered.

\section{Discussion}

Soft-tissue masses of the extraperitoneal spaces (e.g., abdominal

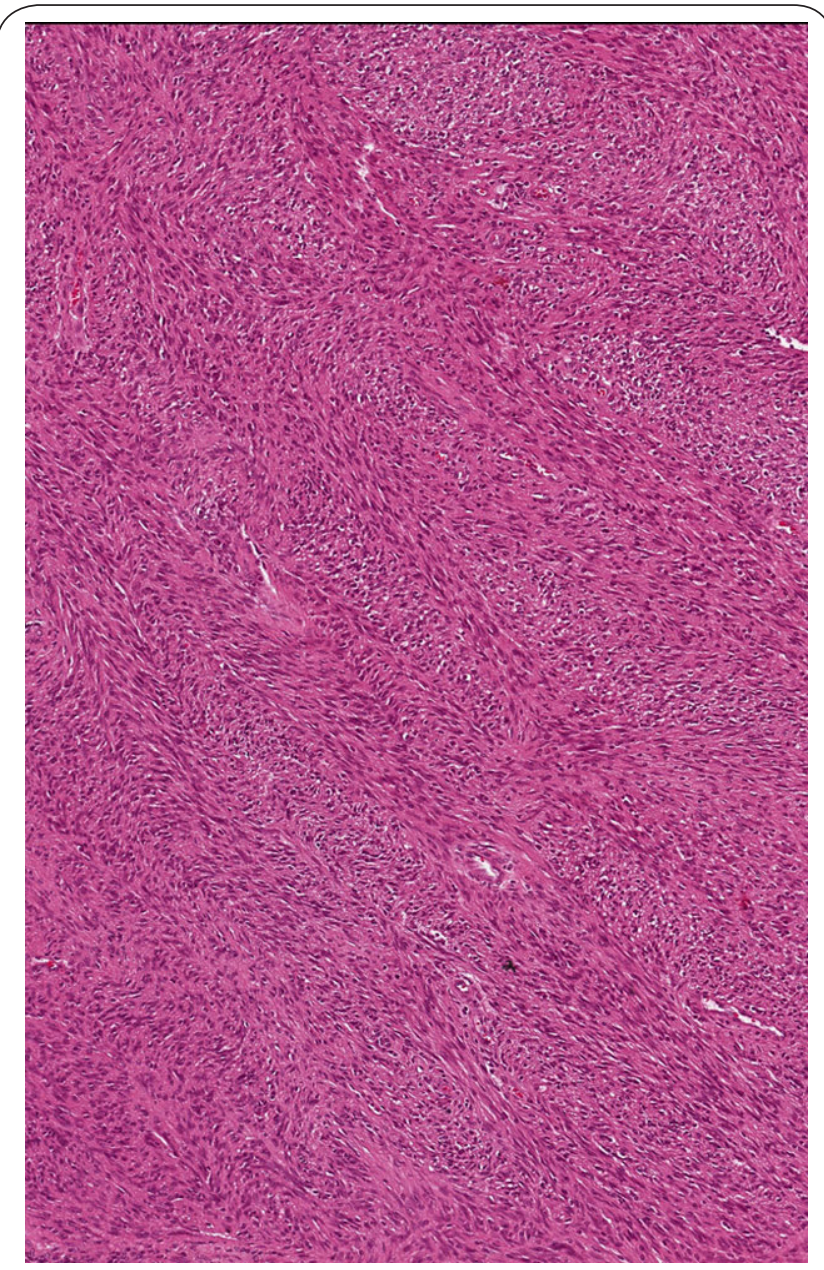

Figure 3. Tumor is composed of bland-looking spindleshaped cells predominantly arranged in intersecting fascicles (haematoxylin and eosin staining; original magnification $\mathrm{x} 100)$. retroperitoneal space, pelvic extraperitoneal space) include a broad spectrum of clinico-pathological entities, whose specific diagnosis cannot usually be achieved by radiologists, due to the considerable overlap in their imaging appearances [43]. However, CT and Magnetic Resonance (MR) imaging findings, especially referred to the nature of tumor stroma (i.e., myxoid stroma, fibrous and sclerotic stroma), the presence of calcifications and tumor fatty component, and the dynamic enhancement patterns, can be helpful in the differential diagnosis of these lesions [43]. We report a case of retroperitoneal CS with emphasis on radiological and pathological features. In our case, CT clearly demonstrated the absence of any fatty component within tumor mass, ruling out the possibility of retroperitoneal lipomatous tumors (lipoma, liposarcoma, mielolipoma). The mass was solid, with a softtissue density, and presented a round central area with lower density, consistent with necrosis. It did not show neither cystic areas nor calcifications and, after e.v. administration of the 


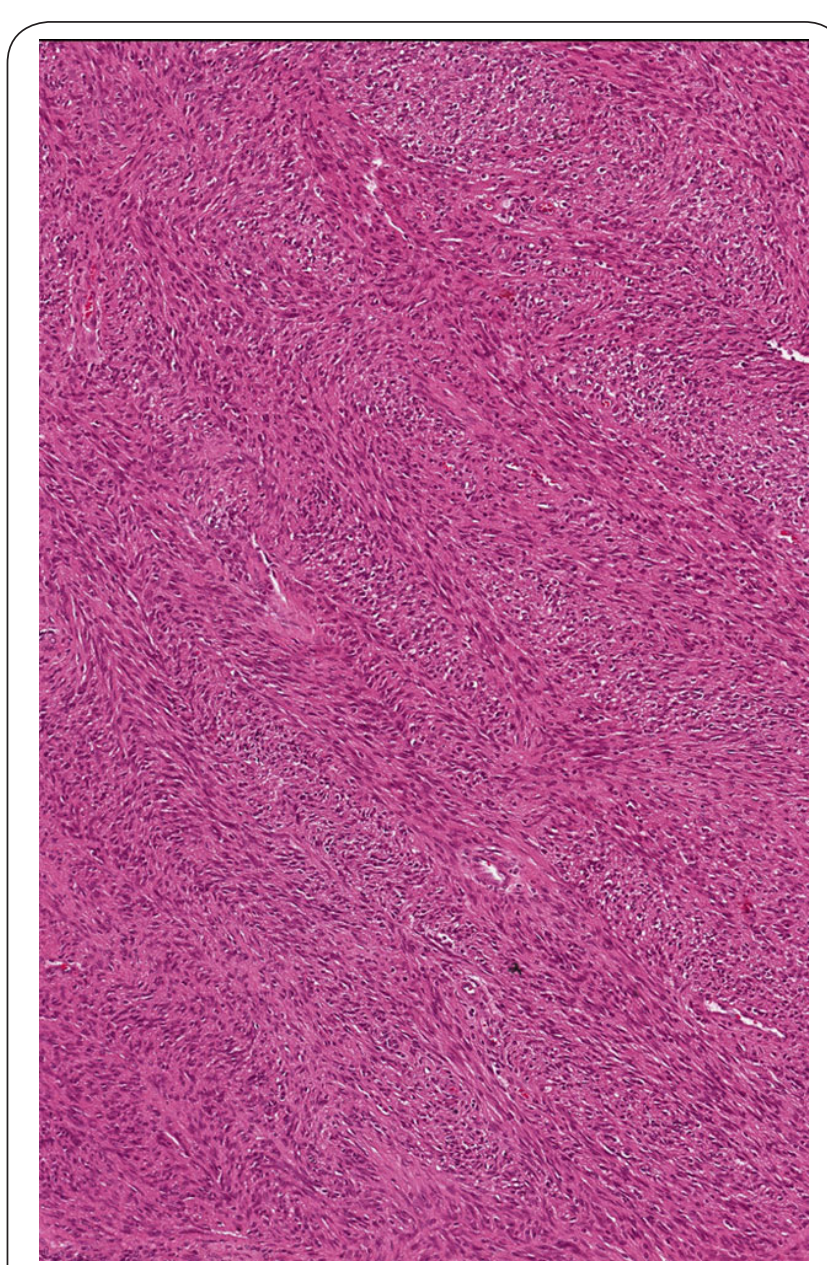

Figure 4. Numerous blood vessels with hyalinized walls were seen throughout the tumor (haematoxylin and eosin staining; original magnification $\mathrm{x} 80$ ).

contrast medium, the enhancement was mild and homogenous as usually seen in a moderately vascularized mass. Although these features were not specific, they were consistent with a densely cellular or fibrous tumor. Radiological distinction between retroperitoneal benign and malignant tumors is usually challenging due to the overlapping of the imaging findings. In this regard, large tumor size, irregular margins and the absence of calcifications may be predictors of malignant tumors [44]. Recently, Zheng and coauthors [45] studied the sensitivity and the specificity of some diagnostic $\mathrm{CT}$ indexes in the prediction of malignancy, evaluating 194 cases of primary retroperitonal tumors and proposed a combined score system. They showed that ill-defined margins, irregular tumor shape, long diameter $(>6.75 \mathrm{~cm})$ and short diameter $(>6.25 \mathrm{~cm})$, and solid texture were statistically significant parameters of malignancy, while $\mathrm{CT}$ attenuation number and calcifications had no statistical significance. In our case, based on large tumor size $(9 \mathrm{~cm})$, solid internal structure, and mainly the ill-defined left margin, in correspondence of which the mass appeared to be not dissociable from the ipsilateral psoas muscle, the

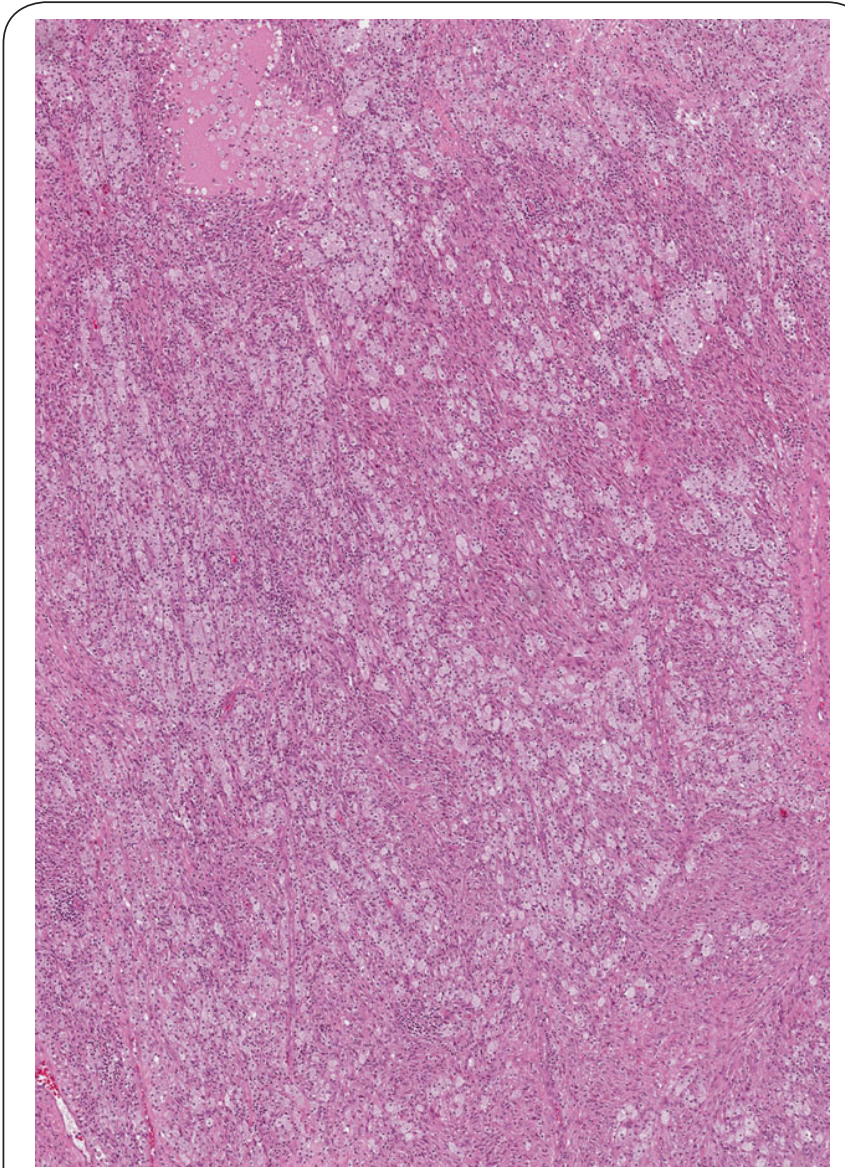

Figure 5. Numerous foamy histiocytes are scattered among neoplastic spindle cells (haematoxylin and eosin staining; original magnification $\mathrm{x} 80$ ).

possibility of a sarcoma was proposed. The hypothesis of a leiomyosarcoma [46] (the second most common primary retroperitoneal sarcoma after liposarcoma) was unlikely because the most commonly affected location is the segment between the diaphragm and renal veins and approximately $6 \%$ of leiomyosarcomas arise from the inferior vena cava that in our case was completely spared; moreover, at CT and MR images, the most suggestive feature for leiomyosarcoma is extensive necrosis with a contiguous involvement of a vessel. Abdominal schwannomas [47] are usually located in the paravertebral regions, adjacent to the kidney or, as in our case, in the presacral pelvic retroperitoneum. They usually occur in young to middle-aged adults, and women are affected twice as often as men. The tumors are generally asymptomatic and therefore discovered incidentally. They are often misdiagnosed as tumors or tumor-like lesions primarily arising from adjacent anatomical structures or organs [44]. Differential radiological diagnosis mainly revolves around myelolipoma, paraganglioma, liposarcoma, leiomyosarcoma, and malignant fibrous histiocytoma [44]. In our case, the neurogenic nature of the tumor was not suspected because imaging did not demonstrate a close relationship between 


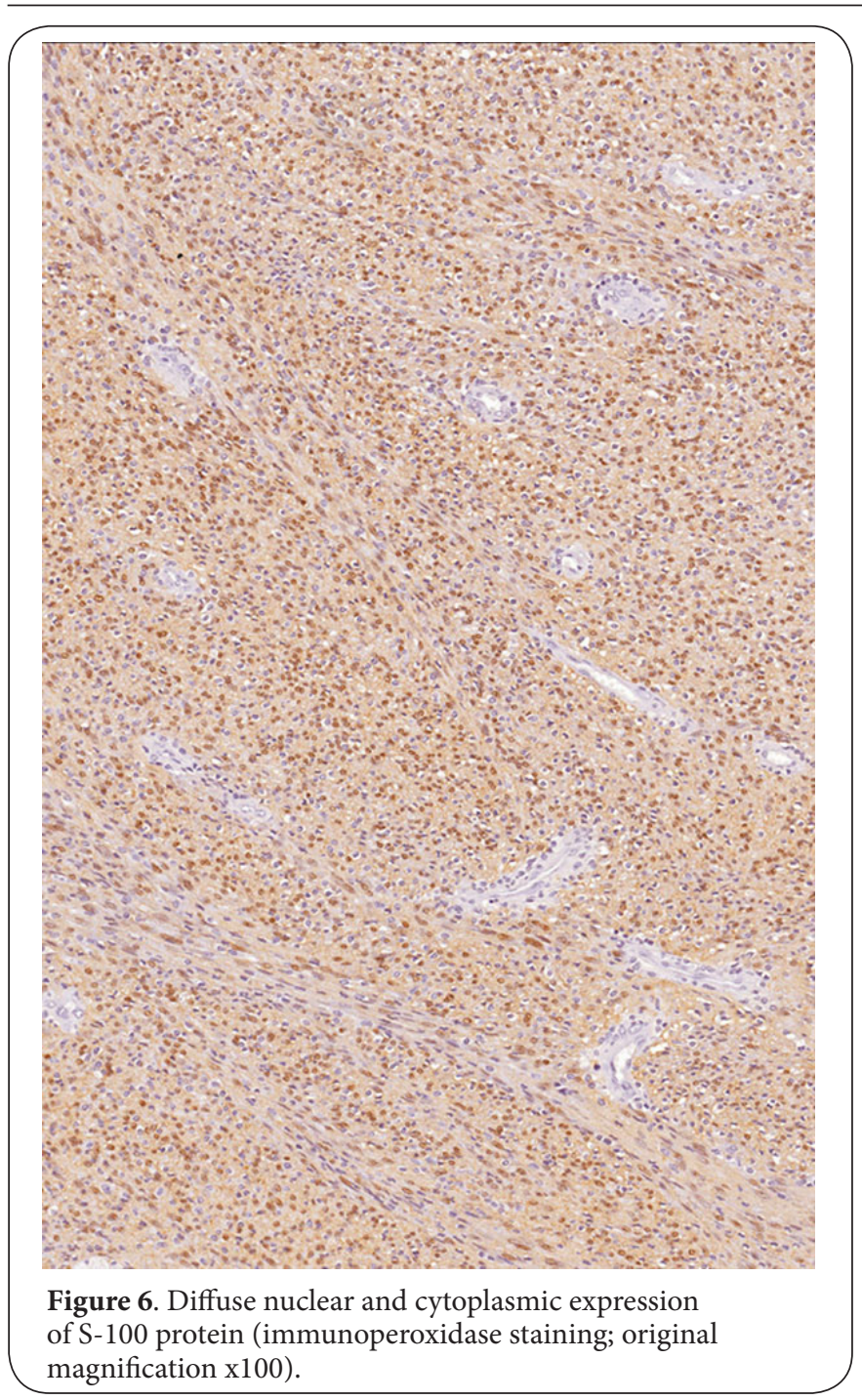

the mass and a conjugation foramen. However, as already reported in literature [47], this is commonly due to the fact that the affected nerve is of small size and it is usually lacking, not only on imaging, but also at histological examination. Retroperitoneal schwannomas usually present as a round to oval-shaped mass with well-defined margins, while their imaging features are quite variable on the basis of their cellularity [47] and extra-cellular matrix composition. In our case, the mass had a homogeneous soft-tissue density, probably due to the high level of diffuse high cellularity. Interestingly, the mass had neither cystic areas nor calcifications, which instead are frequently encountered in schwannomas $[\mathbf{4 4 , 4 8}]$. The enhancement pattern of schwannomas depends on the variation in the degree of cellularity; therefore, unlike our case, in which the enhancement refers to a moderately vascularized mass, a low cellularity with a diffuse edematous change may result in a minimal contrast enhancement [47]. In our case, CT images showed an ambiguous image of infiltration of left psoas muscle but excluded bone erosion. Invasive margins are uncommon in schwannomas, whereas they are occasionally reported in some cases of malignant peripheral nerve sheath tumors [49]. The case of CS herein presented was challenging not only on radiological images, but also on histological examination. This was mainly due to the fact that typical schwannoma shows nuclear palisading, which frequently results in the formation of the "so-called"Verocay bodies, whose detection, even if only focally, is considered to be the hallmark of this benign tumor. In our case, the absence of Verocay bodies, along with a spindle cell tumor with fascicular, storiform, and herringbone patterns, rendered difficult its recognition as schwannoma. Accordingly, the following mainly tumors were included in the differential diagnosis: leiomyosarcoma, adult-type fibrosarcoma, monophasic synovial sarcoma, malignant peripheral nerve sheat tumor and inflammatory myofibroblastic tumor. Although each of these tumors shows distinctive morphological features, CS can be easily distinguished by means of immunohistochemical analyses. Unlike the above-mentioned malignant tumors, CS shows a diffuse $\mathrm{S}-100$ protein, whereas only a focal staining for this marker can be found in both synovial sarcoma and malignant peripheral nerve sheath tumor.

\section{Conclusion}

The present paper emphasizes that CS can occur in the retroperitoneum, representing a potential diagnostic pitfall. Although this unusual variant of schwannoma exhibits some alarming radiological and morphological features, the correct diagnosis can be confidentially achieved if pathologist is aware of this unusual tumor, including S-100 protein in the immunohistochemical panel, when he is dealing with a retroperitoneal spindle cell tumor.

\section{Competing interests}

The authors declare that they have no competing interests.

Authors' contributions

\begin{tabular}{|l|c|c|c|c|c|}
\hline Authors' contributions & FL & GM & GF & CT & GM1 \\
\hline Research concept and design & $\checkmark$ & $\checkmark$ & -- & -- & $\checkmark$ \\
\hline Collection and/or assembly of data & $\checkmark$ & $\checkmark$ & $\checkmark$ & $\checkmark$ & $\checkmark$ \\
\hline Data analysis and interpretation & $\checkmark$ & $\checkmark$ & $\checkmark$ & $\checkmark$ & $\checkmark$ \\
\hline Writing the article & $\checkmark$ & -- & -- & -- & $\checkmark$ \\
\hline Critical revision of the article & $\checkmark$ & $\checkmark$ & $\checkmark$ & $\checkmark$ & $\checkmark$ \\
\hline Final approval of article & $\checkmark$ & $\checkmark$ & $\checkmark$ & $\checkmark$ & $\checkmark$ \\
\hline Statistical analysis & -- & -- & -- & $\checkmark$ & $\checkmark$ \\
\hline
\end{tabular}

\section{Acknowledgement}

This study was supported by grants provided by the Department of Medical and Surgical Sciences and Advanced Technologies, G.F. Ingrassia, Azienda Ospedaliero-Universitaria "Policlinico-Vittorio Emanuele", Anatomic Pathology Section, University of Catania, Catania, Italy.

\section{Publication history}

Editor: Lingyan Wang, Oregon Health \& Science University, Portland. Received: 18-Oct-2014 Final Revised: 19-Nov-2014

Accepted: 26-Nov-2014 Published: 03-Dec-2014 
Longo et al. Journal of Histology \& Histopathology 2014,

http://www.hoajonline.com/journals/pdf/2055-091X-1-14.pdf

doi: 10.7243/2055-091X-1-14

\section{References}

1. Fletcher CDM, Bridge JA, Hogendoorn PCV and Mertens F. WHO Classification of Soft Tissue and Bone. IARC Lyon. $4^{\text {th }}$ Edition. 2013. I Book

2. Weiss SW and Goldblum JR. "Enzinger and Weiss' s SOFT TISSUE TUMORS" $\mathbf{5}^{\text {th }}$ edition. Mosby, Inc., an affiliate of Elsevier. 2008. | Book

3. Bardeguez A, Chatterjee M and Sicuranza B. An unusual case presentation. Cellular schwannoma in pregnancy: an unusual cause of low back pain. J Perinatol. 1989; 9:94-7. | PubMed

4. Hirose T, Ishizawa K, Sakaki M and Fujii Y. Retroperitoneal schwannoma is characterized by a high incidence of cellular type and GFAPimmunoreactivity. Pathol Int. 2012; 62:456-62. | Article I PubMed

5. Mirpuri-Mirpuri PG, Alvarez-Cordoves MM and Perez-Monje A. [Retroperitoneal schwannoma]. Semergen. 2012; 38:535-8. | Article | PubMed

6. Ortiz Rey JA, Alexsandro da Silva E, Rico Gala S, Anton Badiola I, San Miguel Fraile P, Zungri Telo E and de la Fuente Buceta A. [A retroperitoneal cellular schwannoma]. Actas Urol Esp. 1999; 23:455-8. I PubMed

7. Lee MH, Graham AN, Nicholson AG and Pastorino U. Solitary cellular schwannoma presenting with haemothorax. J R Soc Med. 1998; 91:5967. | PubMed Abstract | PubMed Full Text

8. Soria-Cespedes D, Robles-Vidal C, Gomez-Gonzalez A, Penaloza-Ramirez $\mathrm{R}$ and Ortiz-Hidalgo C. Primary pleural hybrid cellular schwannoma/ perineurioma: a case report. Respir Investig. 2014; 52:269-73. | Article I PubMed

9. Domen $\mathrm{H}$, Iwashiro $\mathrm{N}$, Kimura $\mathrm{N}$, Jinushi $\mathrm{E}$, Komuro $\mathrm{K}$, Ohara $\mathrm{M}$ and Ishizaka M. Intrapulmonary cellular schwannoma. Ann Thorac Surg. 2010; 90:1352-5. | Article | PubMed

10. Nesbitt JC, Vega DM, Burke T and Mackay B. Cellular schwannoma of the bronchus. Ultrastruct Pathol. 1996; 20:349-54. | Article I PubMed

11. Inoue M, Maruyama K, Furuhata Y, Kasahara D, Tanaka I and Takemura T. [Cellular schwannoma of the lung]. Nihon Kyobu Geka Gakkai Zasshi. 1992; 40:1951-4. | PubMed

12. Ogose $A$, Hotta $T$, Hatano $H$, Kawashima $H$, Umezu H, Higuchi T and Endo N. Presacral multiple cellular schwannomas. Spine (Phila Pa 1976). 2003; 28:E426-9. | Article | PubMed

13. Wang $G$, Chen $P$, Zong $L$, Shi $L$ and Zhao W. Cellular schwannoma arising from the gastric wall misdiagnosed as a gastric stromal tumor: A case report. Oncol Lett. 2014; 7:415-418. | Article | PubMed Abstract | PubMed Full Text

14. Adlekha $\mathrm{S}$ and Chadha T. Cellular schwannoma arising from sigmoid mesocolon presenting as torsion. Ann Med Health Sci Res. 2013; 3:S33-4. | Article | PubMed Abstract | PubMed Full Text

15. Skopelitou AS, Mylonakis EP, Charchanti AV and Kappas AM. Cellular neurilemoma (schwannoma) of the descending colon mimicking carcinoma: report of a case. Dis Colon Rectum. 1998; 41:1193-6. | Article I PubMed

16. Koyye RT, Mahadevan A, Santosh V, Chickabasaviah YT, Govindappa SS, Hegde T and Shankar SK. A rare case of cellular schwannoma involving the trigeminal ganglion. Brain Tumor Pathol. 2003; 20:79-83. | Article | PubMed

17. De Keyzer L, De Leenheer EM, Claes K and Janssens S. A vestibular schwannoma in a patient with Birt-Hogg-Dube syndrome. Genet Couns. 2014; 25:203-8. I PubMed

18. Ayberk G, Ozveren MF, Uzum N, Tosun O and Akcay EK. Cellular schwannoma of the greater superficial petrosal nerve presenting with abducens nerve palsy and xerophthalmia: case report. Neurosurgery. 2008; 63:E813-4. | Article I PubMed

19. Ishii N, Sawamura Y, Tada M and Abe H. Acoustic cellular schwannoma invading the petrous bone: case report. Neurosurgery. 1996; 38:576-8. I Article I PubMed

20. Erlich SA, Tymianski M and KiehI TR. Cellular schwannoma of the abducens nerve: case report and review of the literature. Clin Neurol Neurosurg. 2009; 111:467-71. | Article | PubMed
21. Mariniello G, Horvat A, Popovic M and Dolenc VV. Cellular dumbbell schwannoma of the hypoglossal nerve presenting without hypoglossal nerve palsy. Clin Neurol Neurosurg. 2000; 102:40-3. | Article

22. Chen WC, Chang YL and Lee YC. A huge cystic cellular schwannoma of the intercostal nerve presenting with dyspnea. Ann Thorac Surg. 2009; 87:1268-9. | Article | PubMed

23. Golge UH, Komurcu E and Yilmaz D. An unusual location for cellular schwannoma. J Coll Physicians Surg Pak. 2014; 24 Suppl 1:S46-7. PubMed

24. See comment in PubMed Commons below Nath AK, Sanmarkan AD, D'Souza M, Basu D and Kadambari D. Non-healing ulcer on the great toe due to cellular schwannoma. Clin Exp Dermatol. 2009; 34:e904-6. I Article I PubMed

25. Pasternack WA and Winter-Reiken DJ. Unusually large cellular schwannoma of the foot. J Am Podiatr Med Assoc. 2005; 95:157-60. I Article I PubMed

26. Tagore KR, Krishna R, Charyulu PA and Latha PP. A rare case of cellular schwannoma in the pharynx. Indian J Pathol Microbiol. 2007; 50:835-7. I PubMed

27. Mocella S, Carner M, Bianchi N, Marino F, Piubello Q and Menestrina F. [Cellular neurilemmoma of the nasopharynx: description of a case]. Acta Otorhinolaryngol Ital. 1987; 7:533-9. | PubMed

28. Perez MT, Farkas J, Padron S, Changus JE and Webster EL. Intrasellar and parasellar cellular schwannoma. Ann Diagn Pathol. 2004; 8:142-50. | Article I PubMed

29. Green AL, Yeh JS, Brydon HL and Carey MP. Cellular schwannoma of the posterior fossa. J Neurol Neurosurg Psychiatry. 2002; 72:677-8. | Article | PubMed Abstract | PubMed Full Text

30. Deruaz JP, Janzer RC and Costa J. Cellular schwannomas of the intracranial and intraspinal compartment: morphological and immunological characteristics compared with classical benign schwannomas. J Neuropathol Exp Neurol. 1993; 52:114-8. | Article | PubMed

31. Huang WT, Chen WJ, Hsu HC, Cheng YF and Eng HL. Retrobulbar cellular schwannoma. Two cases report and review of the literature. Pathol Res Pract. 2003; 199:171-4. | Article | PubMed

32. Koizumi Y, Utsunomiya T and Yamamoto H. Cellular schwannoma in the oral mucosa. Acta Otolaryngol. 2002; 122:458-62. I Article I PubMed

33. al-Otieschan AT, Manohar MB, Gangopadhyay K and Tulbah A. Cellular schwannoma of the paranasal sinuses: initial report of a case. Ear Nose Throat J. 2002; 81:281-4. | PubMed

34. Ogutcen-Toller M, Metin M and Karagoz F. Cellular schwannoma of the mandible: a case report. J Oral Maxillofac Surg. 2001; 59:826-8. | Article I PubMed

35. Redman RS, Guccion JG, Spector CJ and Keegan BP. Cellular schwannoma of the mandible: a case report with ultrastructural and immunohistochemical observations. J Oral Maxillofac Surg. 1996; 54:339-44. | Article | PubMed

36. Ellison DW, MacKenzie IZ and McGee JO. Cellular schwannoma of the vagina. Gynecol Oncol. 1992; 46:119-21. | Article | PubMed

37. Sima X, Zhong W, Chen $\mathrm{H}$, You $\mathrm{C}$ and Huang $\mathrm{S}$. A spinal epidural dumbbell cellular schwannoma in an infant. J Clin Neurosci. 2012; 19:767-9. | Article I PubMed

38. Landeiro JA, Ribeiro CH, Galdino AC, Taubman E and Guarisch AJ. Cellular schwannoma: a rare spinal benign nerve-sheath tumor with a pseudosarcomatous appearance: case report. Arq Neuropsiquiatr. 2003; 61:1035-8. | Article | PubMed

39. Woodruff JM, Scheithauer BW, Kurtkaya-Yapicier O, Raffel C, Amr SS, LaQuaglia MP and Antonescu CR. Congenital and childhood plexiform (multinodular) cellular schwannoma: a troublesome mimic of malignant peripheral nerve sheath tumor. Am J Surg Pathol. 2003; 27:1321-9. | Article | PubMed

40. Alberghini M, Zanella L, Bacchini P and Bertoni F. Cellular schwannoma: a benign neoplasm sometimes overdiagnosed as sarcoma. Skeletal Radiol. 2001; 30:350-3. | Article | PubMed 
41. Henke AC, Salomao DR and Hughes JH. Cellular schwannoma mimics a sarcoma: an example of a potential pitfall in aspiration cytodiagnosis. Diagn Cytopathol. 1999; 20:312-6. I PubMed

42. Woodruff JM, Godwin TA, Erlandson RA, Susin M and Martini N. Cellular schwannoma: a variety of schwannoma sometimes mistaken for a malignant tumor. Am J Surg Pathol. 1981; 5:733-44. | Article I PubMed

43. Nishimura $H$, Zhang $Y$, Ohkuma K, Uchida $M$, Hayabuchi $N$ and Sun $\mathrm{S}$. MR imaging of soft-tissue masses of the extraperitoneal spaces. Radiographics. 2001; 21:1141-54. I Article I PubMed

44. M. Dede, G. Yagci, M.C. Yenen, S. Gorgulu, M.S. Deveci, S. Cetiner and S Dilek. Retroperitoneal benign schwannoma: report of three cases and analysis of clinic-radiologic findings. Tohoku J Exp Med. 2003; 200:93-7.

45. Zhu Z, Zhao X, Zhao Y, Yang L, Zhao J, Dai J and Zhou C. Evaluation of CT findings for the differentiation of benign from malignant primary retroperitoneal tumors. Chin Med J (Engl). 2014; 127:114-9. | Article | PubMed

46. Rajiah P, Sinha R, Cuevas C, Dubinsky TJ, Bush WH, Jr. and Kolokythas O. Imaging of uncommon retroperitoneal masses. Radiographics. 2011; 31:949-76. | Article | PubMed

47. Rha SE, Byun JY, Jung SE, Chun HJ, Lee HG and Lee JM. Neurogenic tumors in the abdomen: tumor types and imaging characteristics. Radiographics. 2003; 23:29-43. I Article I PubMed

48. Alam K, Jain A, Misra A and Khan AH. Cellular schwannoma masquerading as malignant peripheral nerve sheath tumour: a diagnostic dilemma. BMJ Case Rep. 2013; 2013. pii: bcr2012008435. doi: 10.1136/bcr-2012-008435. PMID: 23709140. | Article | PubMed

49. Fletcher CD, Davies SE and McKee PH. Cellular schwannoma: a distinct pseudosarcomatous entity. Histopathology. 1987; 11:21-35. | Article | PubMed

\section{Citation:}

Longo F, Musumeci G, Ferrara G, Trombatore C and Magro G. Retroperitoneal cellular schwannoma (CS): a potential pitfall of malignancy. report of a case and review of the literature. J Histol Histopathol. 2014; 1:14. http://dx.doi.org/10.7243/2055-091X-1-14 